\title{
Температурная зависимость потерь в механическом резонаторе, изготовленном методом прямого сращивания кремниевых пластин
}

\author{
(С) Л.Г. Прохоров ${ }^{1}$, А.В. Светаев ${ }^{1}$, Б.С. Лунин ${ }^{2, \uparrow}$, Н.Р. Запотылько ${ }^{3}$, А.А. Катков ${ }^{3}$, В.П. Митрофанов ${ }^{1}$ \\ ${ }^{1}$ Московский государственный университет им. М.В. Ломоносова (физический фракультет), \\ 119991 Москва, Россия \\ 2 Московский государственный университет им. М.В. Ломоносова (химический фракультет), \\ 119991 Москва,Россия \\ 3 «НИИ „Полюс“ им. М.Ф. Стельмаха», \\ 117342 Москва, Россия \\ IE-mail: luninboris@yandex.ru
}

Поступила в Редакцию 19 августа 2019 г.

В окончательной редакции 5 сентября 2019 г.

Принята к публикации 10 сентября 2019 г.

Охлаждение устройств, изготовленных из монокристаллического кремния, до температуры $123 \mathrm{~K}$, при которой значение его коэффициента теплового расширения проходит через нуль, позволяет повысить их стабильность и снизить шумы. В диапазоне температур (100-295 К) исследованы температурные зависимости потерь (затухания) и изменения резонансной частоты в механическом резонаторе камертонного типа, изготовленном из кремниевых полосок и соединенных методом прямого сращивания. Это позволяет неразрушающим образом контролировать качество соединения, а также выявить особенности поведения и изменения, происходящие на границе раздела с течением времени.

Ключевые слова: кремниевая пластина, прямое сращивание, механический резонатор, нулевое значение коэффициента линейного теплового расширения.

DOI: 10.21883/FTP.2020.01.48778.9245

\section{1. Введение}

В последнее время интерес исследователей вызывают устройства, изготовленные из монокристаллического кремния, работающие при температуре $\sim 123 \mathrm{~K}$, при которой коэффициент теплового расширения (КТР) кремния проходит через нуль. В окрестности этой точки значительно снижается нестабильность, связанная с флуктуациями температуры. Так, например, были разработаны ультрастабильные оптические резонаторы из кремния, работающие при указанной температуре. Их использование для стабилизации частоты лазеров позволило создать уникальные сверхстабильные по частоте лазеры $[1,2]$. В проекте гравитационно-волнового детектора следующего поколения (LIGO Voyager) пробные массы, изготовленные из монокристаллического кремния, будут охлаждаться до $123 \mathrm{~K}$, что позволит подавить термоупругие шумы, ограничивающие чувствительность детектора [3]. С другой стороны, в микроэлектронике, микромеханике и оптоэлектронике широко применяется технология прямого сращивания (direct bonding), позволяющая соединять хорошо очищенные и отполированные кремниевые пластины без использования промежуточного клеевого слоя [4-7]. Эта технология хорошо себя зарекомендовала при работе в области комнатных температур. Интерес исследователей вызывает поведение соединенных таким образом кремниевых элементов при охлаждении до низких температур. В частности, для оптических кремниевых резонаторов и пробных масс гравитационно-волновых детекторов важны высокая временная стабильность и низкие механические потери в соединениях. Механические потери в соединении являются также неразрушающим индикатором качества соединения. Из других методов соединения кремниевых элементов отметим hydroxide catalysis bonding, который обеспечивает высокое качество соединения, но технологически более сложен, чем метод прямого сращивания [8]. Кроме того, в отличие от этого метода, прямое сращивание дает возможность разъединения соединенных деталей без их разрушения, что в ряде случаев является важным фактором [9].

В настоящей работе приведены результаты исследования температурной зависимости (в диапазоне температур 100-295 K) механических потерь и резонансной частоты в камертоне, изготовленном из кремниевых пластинок, соединенных методом прямого сращивания. Анализ этих зависимостей позволяет выявить важные особенности поведения соединения и изменений, происходящих на границе раздела с течением времени.

\section{2. Методика эксперимента}

Камертон, изображенный на рис. 1, собирался из трех кремниевых пластинок, которые изготавливались методом анизотропного химического травления из стандартных кремниевых пластин диаметром 76.2 мм и толщиной 310 мкм. Пластины из недопированного монокристаллического кремния с удельным сопротивлением более 1000 Ом · см, полученного методом зонной плавки, име- 


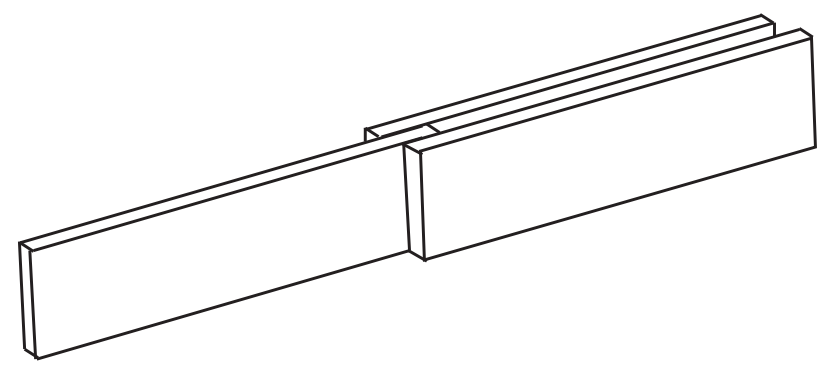

Рис. 1. Камертон, изготовленный из кремниевых пластинок, соединенных методом прямого сращивания.

ли ориентацию поверхности (100) и были отполированы с двух сторон. Шероховатость поверхности пластин, измеренная с помощью профилометра, не превышала 3 нм. Пластинки, ориентированные вдоль кристаллографической оси $\langle 110\rangle$, изготавливались путем протравливания канавок в кремниевой пластине в растворе КОН $30 \%$ концентрации при температуре $80^{\circ} \mathrm{C}[10,11]$. Камертон изготавливался из трех пластинок, соединенных методом прямого сращивания. Для ножки камертона использовалась пластинка длиной 26 мм и шириной 10 мм, для усиков - пластинки длиной 29 мм и шириной 10 мм. Длина области перекрытия пластинок, на которой осуществлялось их соединение, составляла 5 мм. Перед соединением проводилась двухэтапная химическая очистка пластинок. На первом этапе осуществлялась очистка в хромовой смеси $\left(\mathrm{H}_{2} \mathrm{SO}_{4}+\mathrm{K}_{2} \mathrm{Cr}_{2} \mathrm{O}_{7}\right)$ в ультразвуковой ванне в течение 15 мин при температуре $60^{\circ} \mathrm{C}$ с последующей промывкой в деионизированной воде. На втором этапе осуществлялась очистка поверхности пластинок и активация в смеси $\left(\mathrm{H}_{2} \mathrm{O}_{2}+\mathrm{NH}_{4} \mathrm{OH}+\mathrm{H}_{2} \mathrm{O}\right)$ также в ультразвуковой ванне в течение 15 мин при температуре $60^{\circ} \mathrm{C}$. В результате поверхность пластинок становилась гидрофильной, т.е. хорошо смачивалась водой. Гидрофилизация сопровождалась образованием на поверхности пластинок силанольных групп $\mathrm{Si}-\mathrm{OH}$. После этого пластинки промывались в деионизированной воде и высушивались. Их соединение производилось без приложения усилий. Термический отжиг камертона проводился в вакууме, в течение 5 ч при температуре $280^{\circ} \mathrm{C}$. Такой отжиг является так называемым низкотемпературным отжигом в отличие от высокотемпературного, который проводится при температурах выше $400^{\circ} \mathrm{C}$. На следующем этапе поверхность камертона была подвергнута очистке. Очистка от органических загрязнений отожженного камертона производилась раствором „Пиранья“ (смесь серной кислоты и перекиси водорода). Образец находился в растворе в течение 15 мин при температуре $80^{\circ} \mathrm{C}$, после чего он промывался в деионизированной воде и высушивался.

Камертон помещался в вакуумную камеру, откачиваемую турбомолекулярным насосом и охлаждаемую жидким азотом. После заливки азота остаточное давление в камере составляло менее $10^{-6}$ мм рт. ст. При таком дав- лении потери, обусловленные газовым трением [12], давали незначительный вклад в полные потери энергии колебаний камертона. Ножка камертона зажималась между двумя тефлоновыми прокладками, одна из которых была подпружинена для того, чтобы при охлаждении камеры и камертона сила зажима и связанные с ней потери в креплении камертона изменялись незначительно. Место крепления выбиралось в узле колебаний. Его положение рассчитывалось методом конечных элементов. Между ножкой камертона и одной из прокладок помещалась тонкая медная фольга, к которой припаивалась термопара медь-константан, служащая для измерения температуры камертона. Колебания камертона с амплитудой $\sim 10^{-8}$ м возбуждались резонансной электрической силой при приложении переменного напряжения к двум электродам, расположенным на расстоянии $\sim 2$ мм от усика камертона. Регистрация колебаний осуществлялась с помощью оптического сенсора по отклонению лазерного луча, отраженного от колеблющегося усика камертона и падающего на расщепленный фотодиод [13]. Добротность камертона $Q$ определялась по времени затухания его свободных колебаний $\tau: Q=\pi f \tau$, где $f-$ резонансная частота основной моды колебаний камертона. Подробное описание экспериментальной установки представлено в работе [8].

\section{3. Экспериментальные результаты и их обсуждение}

Измеренная при комнатной температуре резонансная частота камертона, изготовленного методом прямого сращивания кремниевых пластинок, составляла 798 Гц. На рис. 2 приведены температурные зависимости механических потерь (затухания) в камертоне $Q^{-1}$, измерен-

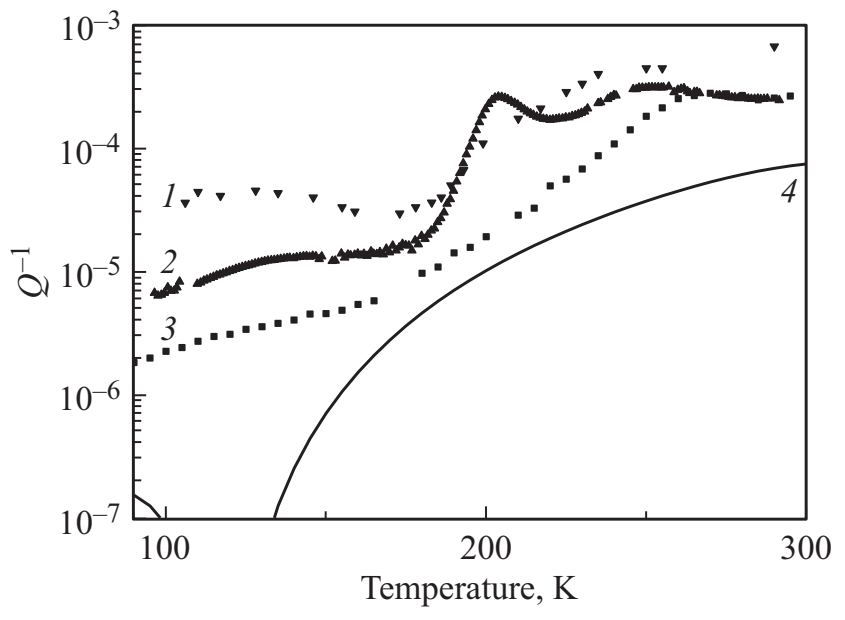

Рис. 2. Температурные зависимости механических потерь $Q^{-1}$ в камертоне, измеренные после различных этапов обработки: 1 - после изготовления, 2 - после термического отжига, 3 - после очистки поверхности; 4 - рассчитанные значения термоупругих потерь. 
ные после основных этапов его изготовления и обработки: после изготовления (кривая 1), после последующего отжига (кривая 2), после очистки (кривая 3). Отметим, что эти измерения проводились по прошествии длительного времени (несколько месяцев) после очередного этапа для того, чтобы соединительный слой пришел в состояние, близкое к равновесному. Из представленных зависимостей можно заключить, что отжиг, проводимый при температуре $280^{\circ} \mathrm{C}$, привел к существенному уменьшению потерь во всем температурном диапазоне, за исключением пика потерь, наблюдаемого вблизи температуры $T=200 \mathrm{~K}$. Это, по-видимому, связано с перестройкой химических состояний на границе раздела и изменением структуры связей [14-16]. Пик потерь не играет принципиальной роли, так как он не проявляется после очистки образца. Как показали измерения, проведенные после окончания переходных процессов в соединении, очистка поверхности камертона не привела к существенному изменению величины потерь, измеренных при комнатной температуре, но снизила потери при низких температурах.

Измеренные потери энергии в колеблющемся резонаторе $Q^{-1}$ определяются суммой вкладов от нескольких основных источников потерь, которые можно представить в следующем виде:

$$
Q^{-1}=Q_{\text {mat }}^{-1}+Q_{\text {sur }}^{-1}+Q_{\text {bond }}^{-1}+Q_{\text {ext }}^{-1} .
$$

Здесь $Q_{\mathrm{mat}}^{-1}$ - потери в материале (кремнии), из которого изготовлен камертон; $Q_{\text {sut }}^{-1}-$ поверхностные потери, включающие потери в приповерхностном слое, нарушенном его шлифовкой и полировкой, а также потери в молекулярных слоях, адсорбированных на поверхности кремния; $Q_{\text {bond }}^{-1}-$ потери в соединительном слое, образующемся на границе раздела при прямом сращивании кремниевых пластинок (свойства границы раздела подробно изучены в работах $[15,17]) ; Q_{\text {ext }}^{-1}-$ потери, обусловленные внешними факторами. К ним относятся передача энергии молекулам остаточного газа и потери в креплении камертона. Как уже было сказано выше, первые давали незначительный вклад в полные потери. Использование в настоящей работе механического резонатора камертонного типа обеспечивало малые потери в его креплении, но их сложно рассчитать, так как свойства механического контакта плохо моделируются.

Потери в материале резонатора можно разделить на внутреннее трение и термоупругие потери. При изгибных колебаниях усиков камертона в областях с деформацией сжатия температура повышается, а в растянутых областях понижается. Между ними возникают тепловые потоки, ведущие к увеличению энтропии и необратимому превращению механической энергии в тепловую. Термоупругие потери $Q_{\mathrm{th}}^{-1}$ могут быть рассчитаны с достаточно хорошей точностью согласно выражению, полученному для изгибных колебаний тонких стержней с прямоугольным поперечным сечением [18]:

$$
Q_{\mathrm{th}}^{-1}=\frac{E \alpha^{2} T \omega \bar{\tau}}{\rho C\left(1+\omega^{2} \bar{\tau}^{2}\right)},
$$

где $E-$ модуль Юнга кремния, $\alpha-$ коэффициент линейного теплового расширения, $T-$ температура, $\rho-$ плотность; $C-$ теплоемкость, $\omega=2 \pi f-$ круговая частота колебаний, $\bar{\tau}-$ характерное время распространения тепла между сжатыми и растянутыми областями. Это время может быть вычислено по формуле [18]

$$
\bar{\tau}=\frac{\rho C t^{2}}{k \pi^{2}},
$$

где $t$ - толщина образца, $k-$ коэффициент теплопроводности кремния.

Для рассматриваемого камертона модуль Юнга берется вдоль кристаллографического направления $\langle 110\rangle$ в соответствии с тем, как вырезаны пластинки [19]. Рассчитанные значения термоупругих потерь в камертоне показаны сплошной линией 4 на рис. 2. Значения термодинамических параметров кремния в зависимости от температуры взяты из литературных источников [20-22].

Термоупругие потери вносят существенный вклад в измеренные потери за исключением области температур вблизи температуры $123 \mathrm{~K}$, при которой коэффициент теплового расширения кремния проходит через нуль. Если вычесть термоупругие потери из полных потерь, измеренных после очистки камертона, то получаем, что эта разность уменьшается от $2 \cdot 10^{-4}$ при комнатной температуре до $3 \cdot 10^{-6}$ при температуре вблизи $123 \mathrm{~K}$. Эти значения существенно превышают значения $Q_{\text {mat }}^{-1}<3 \cdot 10^{-8}$, измеренные в монолитных образцах кремниевых резонаторов в диапазоне температур $100-300 \mathrm{~K}$ [23], т. е. можно считать, что потери в материале (кремнии) много меньше, чем уровень измеренных потерь. Таким образом, можно заключить, что сумма оставшихся потерь (в поверхностном слое, в креплении и в соединении кремниевых элементов) не превышает указанных выше значений. На основании проведенных многочисленных исследований можно предположить, что механические потери в соединении $Q_{\text {bond }}^{-1}$ являются определяющими. Таким образом, согласно проведенным измерениям, $Q_{\mathrm{bond}}^{-1}<3 \cdot 10^{-6}$ при температурах $\sim 123 \mathrm{~K}$.

На рис. 3 (кривые $1-3$ ) представлены температурные зависимости относительного изменения резонансной частоты камертона $\frac{\delta f}{f}=\frac{f(T)-f(293 \mathrm{~K})}{f(293 \mathrm{~K})}$, которая измерялась параллельно с потерями. Нумерация кривых соответствует представленной на рис. 2. Резонансная частота основной моды поперечных колебаний усика камертона $f$ определяется его параметрами и модулем Юнга $E$ согласно уравнению [24]

$$
2 \pi f=\frac{3.52 t}{L^{2}} \sqrt{\frac{E}{12 \rho}},
$$

где $L-$ длина усика камертона. При охлаждении камертона его резонансная частота меняется из-за тем- 
пературных изменений упругих модулей кремния и геометрических размеров полосок, но температурные изменения упругих модулей оказывают основное влияние на изменение собственной частоты [25]. Из рис. 3 можно заключить что, область соединения кремниевых полосок также дает вклад в температурные изменения частоты камертона, изготовленного методом прямого сращивания, причем для более совершенного соединения относительное изменение резонансной частоты становится меньше и приближается к таковому для монолитного резонатора: $\frac{\delta f(T)}{f(293 \mathrm{~K})} \approx 4.4 \cdot 10^{-3}$ при охлаждении от комнатной температуры до $T=100 \mathrm{~K}$ [26].

В процессе исследований потерь в камертоне было обнаружено, что их величина изменяется с течением времени, прошедшего после выполнения очередной процедуры его обработки. Причем временной масштаб изменений составляет много дней. Температурные зави-

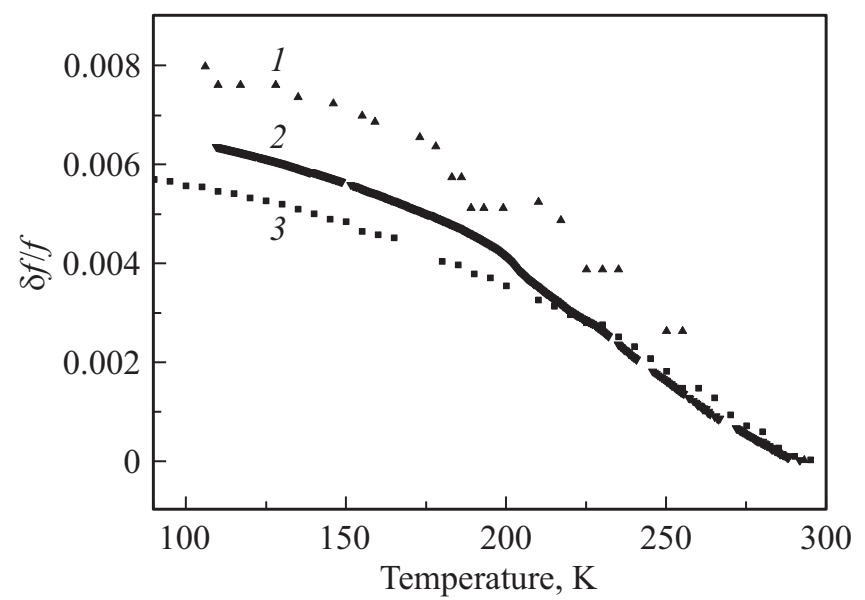

Рис. 3. Температурные зависимости относительного изменения резонансной частоты камертона $\delta f / f$, измеренные после различных этапов обработки: 1 - после изготовления, $2-$ после термического отжига, 3 - после очистки поверхности.

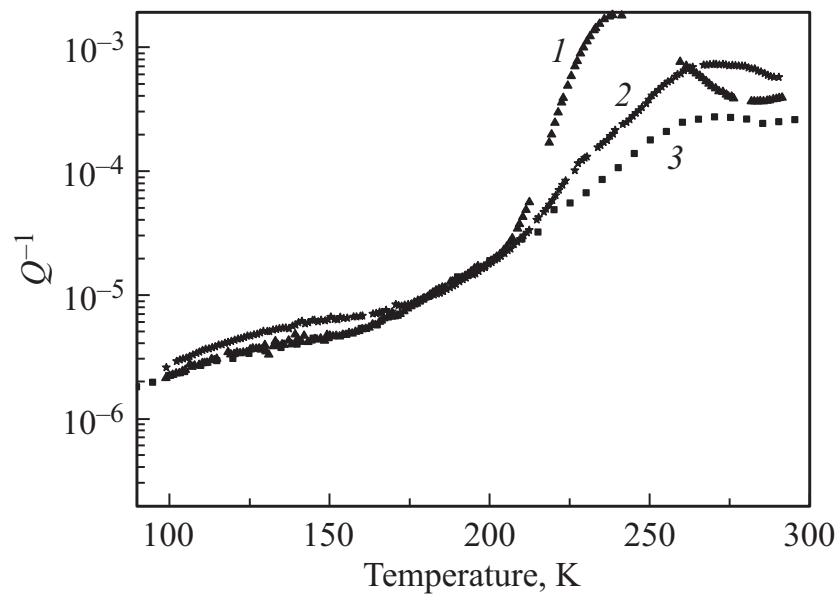

Рис. 4. Температурные зависимости механических потерь $Q^{-1}$ в камертоне, измеренные через: $1-5$ дней, $2-67$ дней и $3-250$ дней после его очистки в водном растворе „Пиранья“. симости потерь в камертоне, измеренные через 5 дней (кривая 1), 67 дней (кривая 2) и 250 дней (кривая 3) после его очистки в водном растворе „Пиранья“, представлены на рис. 4.

На температурной зависимости потерь, измеренных через 5 дней после его очистки, наблюдался пик затухания при температурах вблизи $250 \mathrm{~K}$, который уменьшался со временем и сдвигался в сторону более высоких температур. Заметные изменения происходили в течение, примерно, первых двух месяцев. Отметим, что, несмотря на значительные изменения потерь в температурной области вблизи пика, потери в камертоне, измеренные в интересной для практических применений области температур $\sim 123 \mathrm{~K}$, оставались неизменными в пределах погрешности измерений. Появление пиков на температурной зависимости потерь после очистки сопровождалось увеличением относительного изменения частоты камертона при его охлаждении.

Описанные выше температурные зависимости можно объяснить присутствием воды между контактирующими поверхностями на границе сращивания [15]. При очистке камертона он помещался в водный раствор чистящих реактивов, так что молекулы воды диффундировали в слой на границе сращиваемых пластинок. С присутствием воды на границе, по-видимому, связан релаксационный процесс, проявляющийся в виде пика на температурной зависимости механических потерь в камертоне. После его очистки и помещения в вакуумную камеру происходит обратный процесс диффузии молекул воды из граничного слоя, что приводит к уменьшению величины пиков и сдвигу по температуре их положения. Для проверки этого предположения был выполнен следующий эксперимент. Граница соединения пластинок по ее периметру была смочена водой и оставлена на несколько минут до высыхания. Затем вакуумная камера с образцом была откачана и проведены измерения температурной зависимости потерь и относительного сдвига частоты камертона. Потери в пике увеличились, и он сдвинулся в сторону низких температур на $\sim 15 \mathrm{~K}$. Относительное изменение резонансной частоты камертона $\delta f / f$, измеренное при охлаждении до температуры $100 \mathrm{~K}$, увеличилось на $\sim 7 \cdot 10^{-4}$. Через несколько дней величина потерь и частотного сдвига вернулись к первоначальному уровню, что подтверждает гипотезу о роли воды в формировании пика на температурной зависимости потерь в камертоне.

\section{4. Заключение}

Из проведенных исследований можно заключить, что измерения в диапазоне температур (295-100 K) температурной зависимости потерь в механическом резонаторе - камертоне, изготовленном с применением техники прямого сращивания кремниевых пластинок с последующим низкотемпературным отжигом, позволяют осуществлять неразрушающий контроль качества соедине- 
ния и происходящих со временем изменений в соединительном слое. При температурах, близких к комнатной, наблюдается пик механических потерь, который можно связать с релаксационным процессом в соединительном слое. Высота пика медленно уменьшается с течением времени, прошедшего с момента отжига и очистки, на временах, составляющих несколько месяцев. В отличие от области комнатных температур эта релаксация не проявляется при температурах вблизи $123 \mathrm{~K}$, и измеренные потери находятся стабильно на уровне $(3-4) \cdot 10^{-6}$. Такая величина потерь, хотя и превышает потери в монолитных кремниевых резонаторах, работающих при указанных температурах, но является достаточно низкой и делает механические резонаторы, изготовленные с использованием технологии прямого сращивания кремния, пригодными для многих практических применений. Это свойство соединения кремниевых элементов методом прямого сращивания, проявляющееся в области низких температур, является еще одним преимуществом работы при температуре $123 \mathrm{~K}$ устройств, изготовленных из кристаллического кремния.

\section{Финансирование работы}

Работа выполнена при поддержке гранта РНФ № 17-12-01095.

\section{Конфликт интересов}

Авторы заявляют, что у них нет конфликта интересов.

\section{Список литературы}

[1] T. Kessler, C. Hagemann, C. Grebing, T. Legero, U. Sterr, F. Riehle, M.J. Martin, L. Chen L, J. Ye. Nature Photonics, 6, 687 (2012).

[2] D.G. Matei, T. Legero, C. Grebing, S. Hafner, C. Lisdat, R. Weyrich, W. Zhang, L. Sonderhouse, J.M. Robinson, F. Riehle, J. Ye, U. Sterr. J. Phys.: Conf. Ser., 723, 012031 (2016).

[3] R.X. Adhikari. Rev. Mod. Phys., 86, 121 (2014).

[4] M. Shimbo, K. Furukawa, K. Fukuda, K. Tanzawa. J. Appl. Phys., 60, 2987 (1986).

[5] V. Dragoi, E. Pabo, J. Burggraf, G. Mittendorfer. Microsyst. Technol., 18, 1065 (2012).

[6] E. Higurashi, T. Suga. Electron. Commun. Jpn, 99, 63 (2016).

[7] М.М. Мездрогина, Л.С. Костина, Е.И. Белякова, Р.В. Кузьмин. ФТП, 47, 1204 (2013).

[8] L.G. Prokhorov, D.V. Koptsov, M.S. Matiushechkina, V.P. Mitrofanov, K. Haughian, J. Hough, S. Rowan, A.A. van Veggel, P.G. Murray, G.D. Hammond, K. Tokmakov. Phys. Lett. A, 382, 2186 (2018).

[9] Y.R. Jeon, H. Hoonhee, C. Changhwan. Sensors. Actuators A, 281, 222 (2018).

[10] H. Seidel, L. Csepregi, A. Heuberger, H. Baumgartel. J. Electrochem. Soc., 137, 3612 (1990).

[11] L. Haiberger, D. Jager, S. Schiller. Rev. Sci. Instrum., 76, 045106 (2005).

[12] M. Bao, H. Yang. Sensors. Actuators A, 136, 3 (2007).
[13] N.P. D’Costa, J.H. Hoh. Rev. Sci. Instrum., 66, 5096 (1995).

[14] C. Mai, J. Sun, H. Chen. RSC Advances, 6, 37079 (2016).

[15] T. Plach, K. Hingerl, S. Tollabimazraehno, G. Hesser, V. Dragoi, M. Wimplinger. J. Appl. Phys., 113, 094905 (2013).

[16] И.В. Грехов, Л.С. Костина, Т.С. Аргунова, Е.И. Белякова, Н.М. Шмидт, К.Б. Костин, Е.Д. Ким, С.Ч. Ким. ЖТФ, 71 (6), 45 (2001).

[17] А.Г. Мелехин, С. Himcinschi, М. Friedrich, К. Hiller, M. Wiemer, T. Gessner, S. Schulze, D.R.T. Zahn. ФТП, 40, 1338 (2006).

[18] А. Новик, Б. Берри. Релаксационные явления в кристал$\operatorname{sax}($ М., Атомиздат, 1975) c. 364.

[19] M.A. Hopcroft, W.D. Nix, T.W. Kenny. J. Microelectromech. Syst., 19 (2), 229 (2010).

[20] C.A. Swenson. J. Phys. Chem. Ref. Data, 12,179 (1983).

[21] P.D. Desai. J. Phys. Chem. Ref. Data, 15, 967 (1986).

[22] C.Y. Ho, R.W. Powell, P.E. Liley. J. Phys. Chem. Ref. Data, 1, 279 (1972).

[23] D.F. McGuigan, C.C. Lam, R.Q. Gram, A.W. Hoffman, D.H. Douglas, H.W. Gutche. J. Low Temp. Phys., 30, 621 (1978).

[24] Л.Д. Ландау, Е.М. Лифшиц. Теория упругости (М., Наука, $1965)$ c. 149

[25] U. Gysin, S. Rast, P. Ruff, E. Meyer. Phys. Rev. Lett. B, 69, 045403 (2004).

[26] S. Reid, G. Cagnoli, D.R.M. Crooks, J. Hough, P. Murray, S. Rowan, M.M. Fejer, R. Route, S. Zappe. Phys. Lett. A, 351, 205 (2006).

Редактор А.Н. Смирнов

\section{Temperature dependence of loss in mechanical resonator fabricated using direct bonding of silicon strips}

\author{
L.G. Prokhorov ${ }^{1}$, A.V. Svetaev ${ }^{1}$, B.S. Lunin ${ }^{2}$, \\ N.R. Zapotylko ${ }^{3}$, A.A. Katkov ${ }^{3}$, V.P. Mitrofanov ${ }^{1}$ \\ ${ }^{1}$ Lomonosov Moskow State University \\ (Faculty of Physics), \\ 119991 Moscow, Russia \\ ${ }^{2}$ Lomonosov Moskow State University \\ (Faculty of Chemistry), \\ 119991 Moscow, Russia \\ ${ }^{3}$ POLYUS Research Institute of M.F. Stelmax JSC, \\ 117342 Moscow, Russia
}

\begin{abstract}
Cooling of devices made of monocrystalline silicon to a temperature of $123 \mathrm{~K}$, at which the coefficient of thermal expansion of silicon exhibits a zero crossing, improves their stability and reduces noise. In the temperature range (100-295 K), the temperature dependences of the losses (damping) in a tuning fork mechanical resonator made of silicon strips and connected by direct bonding technique were investigated. This allows nondestructive monitoring of the quality of the bonding, as well as to identify the peculiarities of behavior and changes that occur at the bonding interface over time.
\end{abstract}

